\title{
Reshaping perioperative nursing practice to get the job done: $A$ constructivist grounded theory study
}

Follow this and additional works at: https://www.journal.acorn.org.au/jpn

Part of the Health Services Administration Commons, Health Services Research Commons, Perioperative, Operating Room and Surgical Nursing Commons, and the Surgery Commons

(c) (1)

This work is licensed under a Creative Commons Attribution 4.0 License.

\section{Recommended Citation}

Bingham, Sharon; Walsh, Kenneth; and Ford, Karen (2018) "Reshaping perioperative nursing practice to get the job done: A constructivist grounded theory study," Journal of Perioperative Nursing: Vol. 31 : Iss. 1 , Article 2.

Available at: https://doi.org/10.26550/2209-1092.1021

https://www.journal.acorn.org.au/jpn/vol31/iss1/2

This Article is brought to you for free and open access by Journal of Perioperative Nursing. It has been accepted for inclusion in Journal of Perioperative Nursing by an authorized editor of Journal of Perioperative Nursing. 


\section{Authors \\ Dr Sharon Bingham \\ PhD, MN \\ Unit Coordinator \\ School of Health Sciences, \\ University of Tasmania \\ Professor Kenneth Walsh \\ PhD, Fellow of the Joanna Briggs Institute \\ Professor of Translational Research in \\ Reshaping perioperative nursing practice to get the job done: A constructivist grounded theory study}

Nursing and Midwifery

Conjoint University of Tasmania and

Tasmanian Health Service

Dr Karen Ford

PhD

ADON Research and Practice Development Practice Development Unit, Nursing and Midwifery, Tasmanian Health Service Senior Clinical Lecturer, School of Health Sciences, University of Tasmania

\section{Corresponding author}

Dr Sharon Bingham

School of Health Sciences,

University of Tasmania

E: Sharon.bingham@utas.edu.au

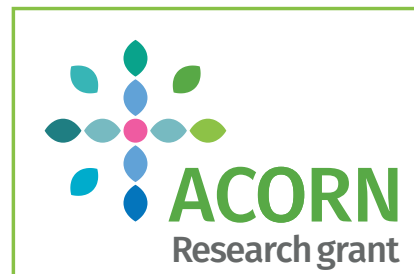

Funding for this research was provided through the 2015 ACORN Research grant.

Every year ACORN offers $\$ 20000$ to support research into perioperative nursing practice.

For more information please go to www.acorn.org.au/education/ grants-and-awards.

Keywords: perioperative nursing, patient safety, rule breaking, constructivist grounded theory

\section{Introduction}

An estimated 234 million operations are performed in hospitals each year and complications of surgery are common and often preventable 1 . The rates of complications vary between studies with reports of perioperative death rates of between 0.4 and 0.8 per cent and rates of complications between 3 and 17 per cent ${ }^{1-5}$. Adverse events can lead to patient disability, death, or increased length of stay, imposing a significant burden on the health care system, patients and their families.

Perioperative nurses have a key role in securing patient safety and preventing mistakes ${ }^{6-15}$ and these are recognised as both the nurses' responsibility and within their locus of control ${ }^{15,16}$. Research and evidencebased actions to minimise the risk of patient harm inform the standards developed by the Australian College of Perioperative Nurses ${ }^{17-28}$. These standards are closely aligned with similar standards in the UK, US and Canada and represent the accepted standard of professional practice for perioperative nurses in Australia.

Notwithstanding the actions taken by the perioperative nurse and the availability of standards, policies, procedures and protocols that support practice, incorrect surgical count incidents continue to occur ${ }^{29-31}$ - patients sustain injuries from poor positioning $32-35$; the inappropriate management of diathermy results in burns ${ }^{36-38}$; surgical fires whilst rare, do strike ${ }^{39-42}$; specimens are mislabelled or go missing ${ }^{43,44}$; incorrect implants are selected and inserted ${ }^{26}$; patients suffer surgical site infections ${ }^{45-51}$; and wrong patient, wrong procedure, wrong site surgery remains a significant issue ${ }^{52,53}$.

Factors that contribute to working in ways other than following rules and standards in the perioperative setting include emergencies, high workloads, poor workflows, productivity pressures, resource availability, deficient communication, inability to deliver timely care, unfamiliarity with technology, and lack of awareness of policies or poor understanding of content ${ }^{54}$. Several studies have found deviations or violations employed as ways of working around rules, policies and procedures $^{54,55}$. The sheer volume of policies and guidelines; multiple rules on the same topic; naming, accessibility, length and complexity; poor version control and the trivial nature of some policies may have the unintended consequence of reducing compliance $^{56}$.

While there are standards and rules that inform and govern practice, nurses at times adopt ways 'other' than following the rules 'to get the job done $e^{\prime 5,55}$. These ways of working are variously identified as violations, deviations, rule-breaking, 
Figure 1: Key concepts and categories

\begin{tabular}{|c|c|c|}
\hline Context & Phenomena & Process \\
\hline $\begin{array}{l}\text { Concept: Enablers } \\
\text { and constraints } \\
\text { to practicing in } \\
\text { accordance with the } \\
\text { rules } \\
\text { Categories: } \\
\text { - Organisational } \\
\text { conditions } \\
\text { - Ambiguity of rules, } \\
\text { tasks, responsibilities } \\
\text { - Team characteristics } \\
\text { - Individual } \\
\text { characteristics }\end{array}$ & $\begin{array}{l}\text { Concept: Being } \\
\text { pressured and feeling } \\
\text { pressured } \\
\text { Categories: } \\
\text { - 'Working with haste' } \\
\text { - 'Push, push, push' } \\
\text { - Weight of expectation } \\
\text { - 'Oh, can we just slow } \\
\text { down' }\end{array}$ & $\begin{array}{l}\text { Concept: Reshaping } \\
\text { practice in response to } \\
\text { pressure to get the job } \\
\text { done } \\
\text { Categories: } \\
\text { - Rule compliance } \\
\text { - 'Toeing the line' } \\
\text { - Making errors } \\
\text { - Rule-breaking } \\
\text { - Using clinical } \\
\text { judgement and } \\
\text { experience }\end{array}$ \\
\hline
\end{tabular}

rule-bending, cutting corners, shortcuts and workarounds $18,23,54,56-59$. The risk is that deviating from rules and standards may lead to an adverse outcome for the patient.

The delivery of high quality perioperative nursing care to attain safe patient outcomes requires sound clinical decision-making, based on an accurate judgment on the most appropriate course of action to take in each situation. Perioperative nurses are continually balancing the imperative to deliver safe care with other demands in a complex, dynamic and rapidly changing environment. There have been few studies that have empirically examined the ways that perioperative nurses work and fewer that have explored the antecedents, attributes and consequences of the different ways of working, and this research aimed to fill this gap. This research explored the way that perioperative nurses perceive, describe, interpret and assimilate into practice the various ways of working and the factors that influence their decision-making.

\section{Statement of purpose and research questions}

This study explored the ways that perioperative nurses worked from the perspective of the nurses themselves. The primary research question was 'What are the ways of working in perioperative nursing and the implications for patient safety and nursing practice?' Secondary questions were:

- What are the conditions that underlie the different ways of working?

- What influences the nurse engaging in different ways of working?

- Are perioperative nurses mindful of working in different ways?

\section{Methods}

This research used constructivist grounded theory, an approach that enables the researcher to be an active participant in generating theory from their own as well as participants' perspectives and experiences and is grounded in the data $^{60}$. Ethics approval to conduct this research was obtained from the
Human Ethics Research Committee (Tasmania) Network (H0014736).

\section{Research setting}

The operating suites of a public and a private hospital in Tasmania were the settings for this study. The two hospitals provided a broad crosssection of specialties and acuity including day surgery and low acuity elective surgery, trauma, emergencies and high acuity neurological and cardiac surgery.

\section{Recruitment}

Six practicing registered and enrolled nurses in scrub and circulating roles from a cross-section of age and length of experience were recruited and gave consent to participate. Each participant was allocated a pseudonym.

\section{Data collection}

Data collection methods included observation of practice, individual face-to-face interviews and memos.

\section{Data analysis procedures}

The participants were observed for a total of 56 hours. Ten hours of interviews were conducted with transcribed interviews entered into a qualitative data analysis software program. The data analysis process included coding and focused coding with codes then grouped together under main headings or categories. Major categories were elevated to concepts. Significant codes and categories were developed into theoretical constructs.

\section{Conceptual framework}

The conceptual framework of context, phenomenon and process organises the key categories and concepts that emerged from the data. 


\section{The substantive theory}

The substantive theory developed was that perioperative nurses 'reshape their practice in response to being pressured and feeling pressured to get the job done'. While the participants mostly complied with standards and rules and expressed a genuine desire to follow them, there were circumstances where they made a conscious decision to work in other ways. Factors within the context of perioperative nursing practice can both constrain and enable practicing in accordance with the rules. Furthermore, constraining factors can lead to 'being pressured' and 'feeling pressured', which in turn constrains practicing in accordance with the rules. Decision-making underpins practice and perioperative nurses employ experience and clinical judgment in making decisions about the way they work. While working in ways other than following the rules is intentional, it is not done with the intention to break the rules, rather it is for another purpose, that is to improve patient outcomes and team and organisational performance.

\section{Findings}

Findings are presented under the headings of context, phenomena and process.

\section{Context: Enablers and constraints to working in accordance with the rules}

While the participants mostly practiced in accordance with rules and standards, there were also instances where they practiced in ways other than following rules and standards. Factors that enabled or constrained working in accordance with rules and standards were found to be:

- organisational conditions

- ambiguity of rules, tasks and responsibilities
- team characteristics

- individual characteristics.

\section{Organisational conditions}

\section{'Being busy'}

'Being busy' may be related to the number of patients on a list, short cases with quick turnovers, doing many tasks and having to focus on tasks unrelated to the patient.

Susan: I find that it gets busy pretty easily and I might be focusing on two or three things.

The participants acknowledge that 'being busy' has implications for their practice. 'Being busy' takes the focus away from the patient on the table.

Claire: Sometimes it does distract me from focusing on the patient, if it all gets too busy.

Jane: It has meant feeling like I've got lots of balls in the air to juggle and I've got to try and keep on top, you know.

\section{'Needing more time'}

Participants referred to the amount of time or lack of time to perform tasks and activities. Some tasks are very time-consuming such as checking trays against the tray list before the procedure. For example, the time-consuming nature of tray checking coupled with limited time to complete all the other necessary tasks can be a constraint to practicing in accordance with the rules.

Susan: If there are two experienced theatre nurses in the theatre you know it can be time-consuming to do a tray list for something that you know well and for a minimal or quite remote risk of losing something in the patient, for example plastic surgery, so it does come down to efficiency sometimes as well.
A consistent thread is the need to balance the competing demands of being there for the patient and the need to complete administrative tasks. Administrative demands take their focus away from patients. Lack of time was found to be the biggest inhibiting factor for making improvements and the non-reporting of things that go wrong. This creates a lost opportunity for improving the systems and processes that support the delivery of safe patient care and many resolvable issues remain within the system to create issues and pressure for others.

\section{Examples of codes under the category 'needing more time' were:}

- 'time, we need more time'

being limited by time

- 'it comes down to a time thing'

non-clinical time

time-consuming

managing time

- saving time

'just one more minute'

pressure of time.

\section{Interruptions and distractions}

Interruptions and distractions take many forms including phone calls, people coming to theatre to ask questions, colleagues talking about non-patient related matters, presence of students and the need to attend to multiple tasks and other responsibilities. Interruptions and distractions may constrain practicing in accordance with rules and standards. For example, a colleague relaying information completely unrelated to the patient on the table interrupts Claire during a count.

Claire: Most people are pretty good when you're counting, unless it's an urgent thing. I thought about restarting the count, but I was very 
confident that I hadn't touched anything and that I had stopped in the middle of the packs, but technically I probably should have started again really. But yes, it is a distraction, so it has the impact of possibly not counting correctly.

\section{'Having a good team'}

The makeup of team can enhance or detract from individual or team performance. The following exemplar illustrates what happens when the participants perceive the team as being 'right'.

Claire: I think it makes a big difference when you get to know each other and I don't mean in a friendship way, but just knowing the skills that individuals have is important in having a good team.

Susan: Lists will seemingly run like clockwork if you've got people thinking on the same level. It's a core team. It's the same team all the time. So, everything runs beautifully in there. Everyone knows what he or she needs to do; everybody knows what is expected of him or her.

Having a good team takes the pressure off individual team members because they can rely on each other to get the job done. Perceiving the skill mix and team make-up to be inadequate can create pressure on the perioperative nurse and affect team performance.

Claire: One of the pressures can be if you haven't got the right skill mix in the theatre, then that can delay cases, delay the day.

The complex nature of perioperative nursing work was evident and nurses were observed adapting and responding to rapidly changing situations.

\section{Team characteristics}

Team characteristics enabled or constrained practicing in accordance with the rules and/or increased or decreased the pressure felt by team members. The two main categories emerging from the data were teamwork and shared goals represented by the concept 'having a good day'.

\section{'Having a good day'}

The experience of the team was integral to the provision of safe patient care and getting the job done. Claire reflects on the importance of having an experienced team during a paediatric list.

Claire: It's safer. It's less stressful for everybody involved to have a skill mix that's right.

Having less experienced team members can adversely affect the performance of the team. In a small team having one less experienced member or one who works at a slower pace can impact on team dynamics and lead to an 'unpleasant day'.

Claire: if you've got staff members that just take more time in what they do, that can slow things down. It makes for a stressful day when you know you've got a long day ahead of you and the surgeon gets crabby at 9:30 and you think 'Oh it's going to be a long day'. Then it can be an unpleasant day. It doesn't have to be an inexperienced person that can make a difference; it can be the way that different people work together.

Factors that influence 'having a good day' include: that everyone in the team does the role he/she is there to do, familiarity, having trust and confidence in each other, good communication and achieving shared goals. Good team dynamics can also enhance job satisfaction and provide a pleasant and relaxed working environment. Shared team goals that are clearly articulated can have a positive impact on team performance.

Researcher: What constitutes a good day?

Sarah: Everything goes smoothly, everything runs efficiently, we work well together, everyone is happy and we've done a good job. There haven't been hiccoughs as well. I think that's a good day.

Being efficient and being seen to be efficient was also a goal. They take pride in the fact that the surgeons do not have to ask for anything, that everything is ready and available. Sarah expressed that in addition to 'having a good day', keeping patients safe is a tacit goal - 'it's a given, it's what we are here for'.

In summary, team members orient themselves to the common task of keeping patients safe and completing the list. How they do this is influenced by the social and organisational context. Team familiarity and cohesiveness affects the wellbeing of the team with 'having a good day' and 'knowing I've done a good job' being significant factors.

\section{Individual characteristics}

The categories relating to individual characteristics were decisionmaking, having experience, having non-technical skills and making a personal choice.

\section{Decision-making}

Participants used the terms 'using common sense', 'it makes sense', 'using experience' and 'using clinical judgment' to describe the decisionmaking process that was occurring when they worked in a certain way. Susan reflects on why she made 
the decision to not check trays for smaller procedures.

Susan: I think you have to use your experience and your judgment and sometimes common sense has to prevail. If it's a small finger for example, you are not going to lose a pair of scissors in there. You may lose them in the linen but I don't feel that jeopardises the patient's safety whereas if I didn't do the tray list on a thoracic case for example or a laparotomy, well that wouldn't sit comfortably with me.

Susan uses a combination of judgement, experience and common sense to underpin the ultimate decision not to check the trays in certain situations. Participants frequently referred to 'using their experience' to inform their decisionmaking in a range of practice situations including whether to break the rules or not in a given situation. Sarah describes the role that experience plays in her decision to not use the tray lists, even though the surgery is in the thoracic cavity.

Sarah: I think it is because we're experienced nurses and that we know the trays so well that we can recognise if something's missing or not right pretty well straight away and because we've got the set trays all the time. There are things that we count in our mind, not openly, but you go through the tray in your own mind when you're getting your instruments out.

There was a close relationship between knowledge, experience and clinical judgement. For example, where Susan made the decision to open a sterile item that had been dropped on the floor.

Susan: Yes, that's right. So there is a certain amount of clinical judgement there and a certain amount of knowledge of your supplies and equipment. Someone more junior might not realise that is the only double-ended 'whatever' that we've got so it is making a judgement call and using your prior knowledge. So, there are a few factors there, I guess.

Even when the participants know what the rules and standards say, the rule or standard is only one factor they consider when making a decision. Other factors such as availability of replacement items, knowledge and experience all play a part in decision-making.

\section{Experience is 'knowing how'}

A team member's experience can moderate/influence behaviour.

Susan: It makes a lot of things easier; it makes you feel comfortable in what you are doing. It allows you to know what you need to do. It allows you to teach other people what you are doing and what to do. In terms of patient safety, it's got to be a benefit to the patient. Again, you know what to do, what's safe practice. If you're scrubbing, you are maintaining the sterile field, you've got the right equipment, you understand the surgery so you can anticipate what the surgeon needs, planning what you are going to do.

Her description conveys a sense of being comfortable in her own professional and personal skin, of knowing what to do and of understanding what is going on. This 'knowing' underpins her ability to anticipate and plan. She recognises the benefit of this 'knowing' for the delivery of safe patient care and for teaching. Experience as described by Susan is an enabler and contributes positively to her own performance, the performance of the team and her ability to deliver safe patient care. Participants identified that 'experience' was not related to how long someone had been a perioperative nurse.

Susan: Just because you've worked in theatre for a long time doesn't mean you are any good at it.

In Claire's eyes the longevity of practice is of less importance than the quality and specific type of experience the nurse has.

Claire: So, it's not experience in years, it's how much a person has worked in that area of surgery, or with that surgeon even.

The notion that the experience the participants speak of is not related to the passage of time or to longevity is expressed by Benner (1984) ${ }^{61}$. Rather than length of time, it is the amount and quality of practice that are key factors in the level of expertise people achieve, indicating that it is not just passage of time that builds experience, it is also the quality of the experiences on the journey ${ }^{62}$. Expertise is gained over the course of time and is shaped by experience ${ }^{63}$.

Participants indicated that the experience of other team members is a positive influence on their own performance and the performance of the team. There is a solid link between experience of the team and ensuring a safe outcome for the patient. With experience comes confidence and lack of confidence of team members can pervade the atmosphere, making the whole team edgy. The following exemplar encapsulates the influence experience has on the team working cohesively to deliver safe patient care and difficulties that can arise when team members are not experienced.

Claire: Probably the best example of when it's really important [having an experienced team] is when we've got paediatric patients. We usually have four staff in a 
theatre. It's the only time we have four staff in a theatre, when we've got paediatric patients. There are two people allocated to anaesthetics to help get the child off to sleep and to look after the parent who's usually there, take the parent out and then continue looking after the patient while they're being intubated or the laryngeal mask is put in. If the whole team isn't experienced in paediatrics ... it's the anaesthetic side of it which can go wrong very quickly. It can be very stressful and dangerous, so that's one situation where it's really important to have the skill mix right.

As discussed above, this research has extended the understanding of the context within which perioperative nurses practice and the factors that influence the perioperative nurse making decisions to work in ways other than following the rules. The next section will interpret and synthesise the finding that perioperative nurses reshape their practice in response to 'being pressured' and 'feeling pressured' to get the job done.

\section{Phenomenon: 'Being pressured'} and 'feeling pressured' to get the job done

Perioperative nurses face daily challenges to get the job done to meet the needs of the patients and the demands of the doctors, the team and the organisation. The context within which perioperative nurses practice was found to contribute to the pressure particularly in the way that it can constrain rather than enable working in accordance with the rules. This research found that in meeting these demands, the participants experienced two different types of pressure. One kind of pressure came from within, created by the expectations of the participants to do the job effectively and efficiently. Dealing with the organisational conditions they faced such as workload, availability of equipment and supplies, supervision of students and the perceived lack of time to complete all necessary tasks also contributed to feelings of pressure. The other pressure came from sources external to the participants - these being the doctors, other team members, team makeup and issues with equipment and supplies. This external pressure created or added to the pressure felt from within. Of significance is that 'being pressured' and/or 'feeling pressured' may increase vulnerability to finding ways of working that overcome perceived barriers and save time.

\section{'Being pressured' to get the job done}

The categories of 'working with haste' and 'push, push, push' capture the codes pertaining to 'being pressured' and these categories form the subheadings for this section.

\section{'Working with haste'}

The perioperative nurse participants often found themselves having to hurry up and work quickly in response to 'being pressured' to get the job done. The participants were asked where the pressure to hurry up and work quickly came from. Their responses highlighted the sources as being doctors, colleagues and the organisation.

Jane: Well, surgeons and anaesthetists don't like to be kept waiting or feeling like they're waiting for longer than they feel is reasonable.

Claire: But we're also very encouraged to have a quick changeover between patients and get on with the list so that people can go and there's not overtime and surgeons aren't kept waiting

and all that sort of thing.

Claire was asked if she felt that pressure made a difference in terms of the way she did things.

Claire: I guess sometimes yes because you might be hurrying up and might not have got some things ready that you should have. The anaesthetist might say 'Come on let's just get the patient in, hurry up' and you'll realise you haven't put the drip up, or you haven't put the ECG dots on the anaesthetic machine. Just little things, but once you get to the point where you need the drip or you're about to put the ECG dots on and then you realise that you haven't got any on the top of the machine and things like that. So, that encouragement to work with haste.

This exemplar demonstrates that the pressure of having to work quickly sometimes led to things not being ready for the next patient. Pressure to work with haste also leads to reprioritising of tasks as described in the next exemplar, with the result that documentation standards are not adhered to.

Claire: I think probably what gets, not missed, but put to the back because it can, is the paperwork. That might be left almost to the end of some short cases and you haven't done anything on the computer or any paperwork because you've been busy doing all that other stuff and there's this speediness and you have not had time to do it. I do think that because of the speed, the count doesn't get written down straight away because you've opened everything, the surgeon is already scrubbed, standing there waiting for the prep and you're doing your count. 
The outcome of having to work with haste is that tasks must be reprioritised and trade-offs made with the result, in this instance, of non-adherence to documentation standards. Pressure leads to working in a way that is not in accordance with the rules.

\section{'Push, push, push'}

The perceived mismatch of available time with the speed of the surgeon, the number of procedures and the type of operations on the list may create pressure before the list even starts. If cases do not go to plan, if complications arise or procedures take longer than expected, more pressure builds on the perioperative nurse to work quickly to achieve the goal of completing the list on time. A constant, often subtle, but ever-present pressure is the surgeon waiting in the background. Perioperative nurses feel pressure to not keep the surgeon waiting to avoid conflict or maintain a productive, collegial atmosphere for the team. They know the consequences of having an unhappy surgeon and work hard to avoid this.

Keeping the surgeon and therefore the team happy constrains the ability of the nurse to adhere to standards of documentation i.e. record the count at the time the item is opened. Claire justifies her decision to leave the paperwork using the low acuity of the cases as the rationalisation for breaking rules. Being pushed to work quickly may result in safety defences being breached and the potential for an adverse event to occur. Joanne recognises this as a barrier to keeping patients safe.

Joanne: I think hurrying and rushing is a barrier to safety. It sometimes causes issues. I can think of a list where the surgeon was 'push, push, push' and that's when there has been an instance of wrong site surgery and why we now push back and not let that happen, we hope.

Jane was asked what pressure looked like for her.

Jane: Expectations for keeping the list moving fairly fast but still providing really good patient care. So, there's the pressure from making sure the list will run smoothly and planning for future lists and patients and all this sort of stuff, which is almost as important as the patient you've got there because they're future patients.

For example, not checking tray lists for familiar trays and completing documentation ahead of time are shortcuts that improve individual, team and organisational performance. Joanne finds herself having to get paperwork done in the morning in preparation for the afternoon list, as she knows she will not have time to do it all when the time comes due to the speed of the surgeon. She is conscious that this is taking her attention away from the patient currently on the table but this is a compromise she feels she has to make to get the job done. Joanne was asked what she prepared in advance.

Joanne: Paperwork. I put data into the computer that isn't essential data that takes a lot of time. I sign the sticker form, I fill the chargeable item numbers on the chargeable form and I put data into the computer that always stays the same. I've actually thought about whether that is a good thing to be doing during someone else's list. I always do it during the morning list, as that surgeon is much slower so I am very aware that I am doing something that is not for that patient. I am always listening and I just leave it and go away from it if the surgeon needs help, so I don't think it is of any detriment to the patient. Whereas, if I left it until the actual list, some of it wouldn't get done because it's not possible to keep up with him.

'Being pressured' and/or 'feeling pressured' may directly influence a decision to practice in ways other than following the rules. For example, the perioperative nurse decides not to recommence the count after an interruption so as not to delay the completion of the procedure and to keep the doctors happy.

Joanne: I think with things like the count, they might not go back to the beginning. You know it says in the standard, if you get interrupted you are supposed to start again. If they are under a lot of pressure, they may say 'where were we, six, ok, seven, eight, nine'. That sort of thing, rather than saying 'no, I'm going to go back'.

Other research has found that constant pressure on workers to increase performance and productivity can lead to the modification of work practices to get the job done ${ }^{59}$.

\section{'Feeling pressured' to get the job done}

This research found that the weight of expectation increases feelings of pressure experienced by the participants. In the following exemplar Jane describes what pressure is for her and how it is driven by the expectations of others in her performance.

Researcher: So, what sort of pressure are the surgeons or the doctors in the team putting on you? What does that look like for you?

Jane: Expectations for keeping the list moving fairly fast but still providing really good patient care. Pressure to achieve. And some of 
that pressure, I know, we put on ourselves. I'm very aware of that. And some is from surgeons. Some is from staff expectations.

Jane acknowledges that she is responsible for some of the pressure she feels and that this may be managed by pausing to reflect on what is causing the pressure and whether it is reasonable and logical to feel that way. However, in the busyness of the day, time for reflection is scarce and the participants' desire to make the list run smoothly can override taking time out to reflect. Sarah takes pride in her operating lists running smoothly and considers it to be a key part of her role that surgeons have everything they need and don't have to ask for anything. This is an expectation she has of her own performance and, like other participants, when supplies and equipment are not available this creates pressure for her.

Sarah: I had on my list, 'I must order this, this and this'. Now, if I don't get a chance to do it for a couple of days then there's a bit of pressure to make sure that I do get that equipment here, even though I don't let the last thing run down to nothing, but I want it here so I know that if the surgeon has asked for something - we've never run out of stock or anything. And, I guess, if there's going to be any pressure, that's on me knowing that I've done a good job and they don't have to worry about that sort of stuff. That's a bit old-fashioned but that's my own personal standard, that I will always want to make sure that this theatre will run well for the surgeons and they've got no cause to worry about it.

Perioperative nurses want to do a good job but the weight of expectation when faced with problems that are often outside of their control can create significant pressure for them.

\section{The process of reshaping practice to get the job done}

In responding to the pressures to get the job done the participants engaged in a process of 'reshaping practice', highlighting what perioperative nurses actually do when they encounter barriers or pressures that compromise or limit their ability to get the job done. In reshaping practice the participants use clinical judgment and experience to make decisions to work in ways other than following the rules. Perioperative nurses respond to pressure to get the job done by working in several different ways: complying with the rules, toeing the line, making errors and breaking the rules. While on most occasions participants practiced in accordance with rules and standards, there were several instances where they practiced in ways other than following the rules. The phenomena of 'feeling pressured' and 'being pressured' were present during many instances of rule-breaking. Decisionmaking, experience and clinical judgment are significant categories that connect the context and the phenomena with the process of reshaping practice.

\section{Discussion}

This research has uncovered a deeper understanding of the way the participants make decisions to work in ways other than following the rules. The context within which perioperative nurses work creates an environment vulnerable to errors and violations and where quick fixes to get the job done become tempting ${ }^{58}$. Constraining factors, at times, led to 'being pressured' and 'feeling pressured' to get the job done which, in turn, constrained practicing in accordance with the rules. In deciding to work in ways other than following the rules, participants 'reshaped' their practice in response to pressure to get the job done.

The phenomena of 'being pressured' and 'feeling pressured' contributes to the decision-making process in that it provides on many occasions the impetus that drives the decision. The process of 'reshaping' practice incorporates making decisions about when rules and standards can be modified to respond to the pressure to get the job done. The memo below is a reflection on the ways that participants reshaped their practice.

Memo (13 July 2016):

Susan made the decision to deviate from the standard requiring the trays are checked to save time and be more efficient. She justified this practice by bringing it back to the patient in that she was assuring the list progressed and patients scheduled later on the list were not cancelled. Claire opened her own supplies into a bowl before she scrubbed to save time and eliminate the pressure she would otherwise have felt to be ready for the surgeon. She justified the practice by bringing it back to the patient who would otherwise be anaesthetised for longer due to the delay in the scout being able to open supplies for her.

Sarah made the decision to remove instruments from the theatre after the initial count and before the final count in response to the pressure of not having the appropriate equipment ready for future cases. She justified this practice by bringing it back to the next patient who may be delayed or have surgery cancelled if the equipment is not processed in time.

In each of these situations, the participants reshaped their practice in response to the situation at hand, 
motivated by pressure to get the job done but at the same time having the patient's best interests in mind.

The way that nurses work is not necessarily the same as the way others think they work. The rules, standards and policies that govern practice are based on employing organisations, regulators and professional bodies understandings of what the work looks like and how that work is performed. However, there is often a mismatch between what they think 'is done' versus what is actually done.

Shorrock et al. ${ }^{64}$ calls work that others think you do 'work as imagined' and the messy work people actually do 'work as done' with three assumptions underpinning 'work as imagined'. Firstly, an organisation is like a complicated machine; secondly, humans are a hazard and, thirdly, things go wrong and things go right for different reasons. Shorrock et al. ${ }^{64}$ argue these assumptions lead to a focus on what goes wrong rather than the routine day-to-day performance where most things go right as well as exceptional performance.

Shorrock et al. ${ }^{64}$ challenges these assumptions. Firstly, an organisation is a complex organism and not a machine. A system is more complex than a machine with intricate interrelationships and one part of the system failing can have significant flow-on effects on the rest of the system. For example, a patient arriving late for a surgical admission may lead to a change in order of the operating list, the correct equipment and supplies for the new patient may not be available and a change to order will increase the risk of wrong patient/wrong procedure/ wrong site surgery. Secondly, humans are an asset rather than a hazard; they perform well the majority of times and very rarely does anyone go to work with the intention of doing harm. We make trade-offs and compromises to make the system work well and do what makes sense at the time, considering the context and situation at hand. Safety is created by adjusting, adapting and varying our performance and if we all stuck to the rules all of the time, the system would struggle. Thirdly, current thinking is that things go wrong and things go right for the same basic reasons. It is the ability of the system to adjust and adapt to the conditions that leads to success or failure ${ }^{6-67}$.

The notion of 'work as done' as being the messy reality of the daily work of perioperative nurses is consistent with the work of Schon (1987) ${ }^{68}$ and Street ${ }^{69}$ on the high ground and swamps of practice.

In the varied topography of professional practice, there is a high hard ground overlooking a swamp. On the high ground, manageable problems lend themselves to solution through the application of research-based theory and technique. In the swampy lowland, messy confusing problems defy technical solution ... The practitioner must choose. Shall he remain on the high ground where he can solve problems according to prevailing standards of rigor, or shall he descend to the swamp. ${ }^{68 \text { p.3 }}$

This research highlights that perioperative nurses do not deliberately 'flout' the rules. I.e. it is not rule-breaking with impunity 'they genuinely try to follow the rules'. In the messy swamps of practice, perioperative nurses apply their clinical judgment and common sense and do what they think needs to be done. That this breaks rules does not appear to be an important consideration in the decision-making process. In the 1980s academics were discussing how to close the gap between theory and practice and proposed a new pathway that recognised the values and practices of practitioners ${ }^{69}$. It is apparent that the path is still unclear and there has been little study on 'work as done' versus 'work as imagined'. This research has taken a step to addressing this issue by highlighting that there is still a gap between what the standards and rules say and how perioperative nursing is practiced.

\section{Recommendations}

It is paramount that any response to the findings from this research includes the employing organisation, the profession, the nursing education sector and individual perioperative nurses. The organisation should work toward harnessing the knowledge and experience of perioperative nurses by engaging them in discussions about 'work as done', to better understand the demands, pressure, resources and constraints that affect performance. This includes recognising the value of teamwork in patient safety and reducing the volume, complexity and ambiguity of rules. The profession should seek to establish forums for perioperative nurses to provide feedback and discussion on 'work as done' and use these to inform development and amendment of standards. Moving towards principlebased rather than prescriptive standards to facilitate the use of a range of techniques may achieve the same outcome. Developing strategies to engage perioperative nurses in using the standards as the benchmark for best and safest practice will enhance professional practice and patient safety.

The nursing education sector should focus to a greater degree on the development of non-technical skills and enhancing the resilience of nurses to better manage the pressure 
inherent in the clinical setting. The individual perioperative nurse should speak up and articulate the knowledge embedded in the practice of perioperative nursing to bring to life everyday practices and offer them up to the profession for scrutiny and testing to ensure they are safe.

Communicating with the organisation and professional body those circumstances and situations where standards and rules are seen to be unnecessary, out of date, inaccessible, unreadable, unworkable and/or unable to be complied with or where there is a more effective or efficient way of working to achieve the same or a similar outcome will assist in driving change. The use of the ACORN standards by all perioperative nurses will set the benchmark for best and safest practice.

\section{Conclusion}

This research addressed the question of the ways that perioperative nurses work and the implications for patient safety and nursing practice. It uncovered that at times perioperative nurses break the rules when they encounter barriers or challenges that compromise or limit their ability to get the job done. The data shows that decisions to work in ways other than following the rules are influenced by several factors including organisational conditions; ambiguity of rule, task and responsibility; team characteristics and individual characteristics. These factors craft the context within which perioperative nurses practice and create the phenomena of 'being pressured' and 'feeling pressured'. The participants respond to this pressure by engaging in a process of reshaping their behaviour. Together these concepts form the substantive theory that perioperative nurses 'reshape their practice in response to being pressured and feeling pressured to get the job done'. This research has uncovered the role that being pressured and feeling pressured plays in the participants' decisions to reshape practice and work in ways other than following the rules. These phenomena have not been explored in other studies and as such this finding adds to our body of knowledge on the factors that impact on rule-breaking.

Rule-breaking in perioperative nursing is not well understood and there has been little research on this topic. This research has contributed to and extended our understanding of why perioperative nurses deviate from rules and standards. The phenomenon of being pressured and feeling pressured is another factor that impacts on knowingly deviating from rules and standards giving rise to the basic social process of reshaping practice in response to pressure.

\section{Acknowledgements}

I was awarded the 2015 ACORN National Research grant which assisted with this research.

\section{References}

1. Haynes AB, Weiser TG, Berry WR, Lipsitz SR, Gawande AA, Breizat AHS et al. A surgical safety checklist to reduce morbidity and mortality in a global population. N Engl J Med 2009;360(5):491-499.

2. Leape LL, Lawthers AG, Localio AR, Barnes BA, Hebert L, Newhouse JP et al. The nature of adverse events in hospitalized patients: Results of the Harvard medical practice study II. N Engl J Med 1991;324(6):377-384.

3. Wiegmann DA, El Bardissi AW, Dearani JA, Daly RC, Sundt TM. Disruptions in surgical flow and their relationship to surgical errors: An exploratory investigation. Surgery 2007;142(5):658-665.

4. Wilson RM, Runciman WB, Gibberd RW, Harrison BT, Newby L, Hamilton JD. The quality in Australian health care study. Med J Aust 1995;163(9):458-471.

5. Anderson O, Davis R, Hanna GB, Vincent CA. Surgical adverse events: A systematic review. Am J Surg 2013;206(2):253-262.
6. Alfredsdottir H, Bjornsdottir K. Nursing and patient safety in the operating room. J Adv Nurs 2008 61(1):29-37.

7. Beyea SC.Patient safety goals: A perioperative nursing priority. AORN J 2008;88(3):459-462 (erratum in AORN J 2008;88(5):714).

8. Farrell VE, Davies KA. Patient safety first. Shaping and cultivating a perioperative culture of safety. AORN J 2006;84(5):857.

9. Joy J. Patient safety first. Nurses: The patient's first - and perhaps last - line of defense. AORN J 2009;89(6):1133-1136.

10. Kleinbeck SVM. In search of perioperative nursing data elements. AORN J 1996;63(5):926-931.

11. Lamberg E, Salantera S, Junttila K. Evaluating perioperative nursing in Finland: An initial validation of perioperative nursing data set outcomes. AORN J 2013;98(2):172-185.

12. McNamara SA. Perioperative nurses' perceptions of caring practices. AORN J 1995;61(2):377, 380-388.

13. Rauta S, Salantera S, Nivalainen J, Junttila K. Validation of the core elements of perioperative nursing. J Clin Nurs 2013;22(910):1391-1399.

14. Steelman VM, Graling PR. Top 10 patient safety issues: What more can we do? AORN J 2013;97(6):679-701.

15. Chard R. How perioperative nurses define, attribute causes of, and react to intraoperative nursing errors. AORN J 2010;91(1):132-145

16. Meeusen V, Mangnus C, Masters S. Locus of control profile in anaesthetic nurse and theatre nurse students: A recruiting guideline. ACORN 2017;30(3):33-37.

17. Australian College of Operating Room Nurses Ltd (ACORN). Standards for Perioperative Nursing in Australia $14^{\text {th }}$ ed. Adelaide, South Australia: ACORN; 2016.

18. Battie R, Steelman VM. Accountability in nursing practice: Why it is important for patient safety. ACORN 2015;28(4):14-16.

19. Davies M, Sutherland-Fraser S, Hazelman M, Williams C. Developing standards in Pacific Island countries: The Pacific perioperative practice bundle (part 1). ACORN 2016;29(2):42-47.

20. Davies M, Sutherland-Fraser S, Raddie N, Taoi N, Hazelman M. Implementing standards in Pacific Island countries: The Pacific perioperative practice bundle (Part 2). ACORN 2017;30(1):41-48.

21. Osborne S. Recent updates to our national standards. ACORN 2016;29(1):54-55. 
22. Johnson J, Osborne S. Surgical hand antisepsis, gowning and gloving - not necessarily the way it has always been done. ACORN 2016;29(2):52-54.

23. Steel C. Communication for safety: Recommendations for ACHS accreditation assessment. ACORN 2016;29(1):26-29.

24. Smalley P, Cubitt, J. Clear air in surgery - a new ACORN initiative. ACORN 2015;28(3):3839.

25. Nicholson P. Getting a handle on instrument loan sets and reusable medical devices. ACORN 2015;28(4):41-42.

26. Lowry KJ, McGrath S, Mihalko WM. The impact of standardized implant labels. American Association of Orthopaedic Surgeons 2014;8(8)

27. Levada L. Updating ACORN standard 'Post Anaesthesia Care Unit nurse'. ACORN 2016;29(3):48-50.

28. Jensen J, Shipp D. Labelling in perioperative areas - an evolving process. ACORN 2015;28(4):10-13.

29. Rowlands A, Steeves R. Research: Incorrect surgical counts: A qualitative analysis. AORN J 2010;92(4):410-419.

30. Thomas J, Adcock F. A review of existing count practice in the operating suite to achieve best practice and safe patient care. ACORN 2014;27(1):20, 22, 24-26.

31. Gillespie BM, Pearson E. Perceptions of self-competence in theatre nurses and operating department practitioners. ACORN 2013;26(1):29-34

32. Murphy EK. OR nursing law. Negligence cases concerning positioning injuries. AORN J 2004;80(2):311.

33. Derieg S. An overview of perioperative care for paediatric patients. ACORN 2017;30(3):2329.

34. Mangham M. Positioning of the anaesthetised patient during robotically assisted surgery: Perioperative staff experiences. ACORN 2017;30(1):20-22.

35. Spruce L, Van Wicklin SA. Back to basics: Positioning the patient. ACORN 2016;29(2):1417.

36. Russell MJ, Gaetz M. Intraoperative electrode burns. J Clin Monit Comput 2004;18(1):25-32.

37. Saaiq M, Zaib S, Ahmad S. Electrocautery burns: Experience with three cases and review of literature. Ann Burns Fire Disasters 2012;25(4):203-206.

38. Webb JB, Balaratnam S, Park AJ. Flame burns: A forgotten danger of diathermy? Surgeon 2003;1(2):111-113.

39. Rocos B, Donaldson LJ. Alcohol skin preparation causes surgical fires. Ann R Coll Surg Engl 2012;94(2):87-89.
40. Watson DS. Patient safety first: Looking back, looking forward. AORN J 2006;84(1):21-24.

41. Zahiri HR, Skupsky H, Knepp EK, Folstein $M$, Silverman $R$, Singh D, Stromberg J. Prevention of 3 'never events' in the operating room: Fires, gossypiboma and wrong-site surgery. Surg Innov 2011;18(1):5560.

42. Stankiewicz M, Wyland M. A review of suspected antiseptic burns intraoperatively: A quality improvement review. ACORN 2017;30(4):25-29.

43. Slavin L, Best MA, Aron DC. Gone but not forgotten: The search for the lost surgical specimens: Application of quality improvement techniques in reducing medical error. Qual Manag Health Care 2001;10(1):45-53.

44. Makary MA, Epstein J, Pronovost PJ, Millman EA, Hartmann EC, Freischlag JA. Surgical specimen identification errors: A new measure of quality in surgical care. Surgery 2007;141(4):450-455.

45. Spelman DW. Hospital acquired infections. Med J Aust 2002;176(6):286-291.

46. Hopper WR, Moss R. Common breaks in sterile technique: Clinical perspectives and perioperative implications. AORN J 2010;91(3):350-367.

47. Liu LQ. The effects of surgical hand scrubbing protocols on skin integrity and surgical site infection rates: A systematic review. ACORN 2017;30(2):21-30.

48. Levada L, Osborne O. Skin preparation of the patient - more than skin deep. ACORN 2017;30(2):57-59.

49. Levada L. Asepsis: The vanguard of infection control. ACORN 2015;28(3):42-43.

50. Spruce L. Back to basics: Preventing surgical site infections. ACORN 2016;29(3):13-18.

51. Sinnott MJ, Eley RM. Staff safety first - a priority in the operating room. ACORN 2015;28(2):8-11.

52. Clarke JR, Johnston J, Finley ED. Getting surgery right. Ann Surg 2007:246(3):395-403.

53. Hanchanale V, Rao AR, Motiwala H, Karim OM. Wrong site surgery! How can we stop it? Urol Ann 2014;6(1):57-62.

54. Debono DS, Greenfield D, Travaglia JF, Long JC, Black D, Johnson J et al. Nurses' workarounds in acute healthcare settings: A scoping review. BMC Health Serv Res 2013;13:175

55. Halbesleben JR, Wakefield DS, Wakefield BJ. Work-arounds in health care settings: Literature review and research agenda. Health Care Manage Review 2008;33(1):2-12.

56. Carthey J, Walker S, Deelchand V, Vincent C, Griffiths WH. Breaking the rules: Understanding non-compliance with policies and guidelines. BMJ 2011;343:d5283.
57. Reason J. Safety in the operating theatre - Part 2: Human error and organisational failure. Qual Saf Health Care 2005;14(1):5660.

58. Reid JH. Violations and migrations in perioperative practice: How organisational drift puts patients at risk. J Perioper Pract 2014;24(3):45-49.

59. Amalberti R, Vincent C, Auroy Y, de Saint Maurice $G$. Violations and migrations in health care: A framework for understanding and management. Qual Saf Health Care 2006;15(Suppl 1):i66-71.

60. Charmaz K. Constructing Grounded Theory. 2nd ed. London: Sage; 2014.

61. Benner P. From novice to expert: Excellence and power in clinical nursing practice. Menlo Park, California: Addison-Wesley, 1984.

62. Ericsson KA, Prietula MJ, Cokely ET. The making of an expert. Harvard Business Review 2007;85(Jul-Aug):114-121, 193.

63. Scholes J, Albarran JW, Williams C. Developing expertise in critical care nursing. Oxford: Wiley; 2006.

64. Shorrock S, Leonhardt J, Licu T, Peters C. Systems thinking for safety: Ten principles. A white paper - Moving towards safetyII [Internet]. Brussels: Eurocontrol; 2014 August [cited 2016 June]. Available from: www.skybrary.aero/bookshelf/books/2882. pdf..

65. Carthey J. Understanding safety in health care: The system evolution, erosion and enhancement model. J Pub Health Res 2013;2(3):e25.

66. Hollnagel E, Wears RL, Braithwaite J. From safety-I to safety II: A white paper [Internet]. The Resilient Health Care Net; 2015. Available from: www.resilienthealthcare.net/ onewebmedia/WhitePaperFinal.pdf

67. Wears RL, Hollnagel E, Braithwaite J (eds). Resilient heath care: Volume 2: The resilience of everday clinical work. Farnham: Ashgate; 2015.

68. Schon D. Educating the reflective practitioner: Toward a new design for teaching and learning in the profession. USA: Wiley, 1987.

69. Street A. Nursing practice: High, hard ground, messy swamps and the pathways in between. Geelong: Deakin University Press; 1990. 